\title{
A EDUCAÇÃO COMO DIREITO DE CIDADANIA E RESPONSABILIDADE DO ESTADO
}

\author{
PEDRO GOERGEN*
}

RESUMO: O objeto do presente estudo é refletir sobre a relevância da educação como direito e condição de cidadania e a função do Estado como responsável pela realização deste direito. O trabalho divide-se em três partes, sendo a primeira dedicada à recuperação histórica dos pressupostos da relação entre o público e o privado no início da modernidade. O segundo ponto trata da educação como condição do exercício da cidadania, destacando o papel da educação escolar formal neste processo. O último tópico discute a responsabilização do Estado como garantia de acesso à educação como meio incondicional para a cidadania. Recuperando as ideias liberais do início da Modernidade e contrariamente às atuais teses neoliberais, defende-se o ponto de vista de que a atuação do Estado como garantia da educação de qualidade para todos é imprescindível.

Palavras-chave: Educação como bem público. Educação como direito. Educação e Estado. Cidadania. Individualidade e socialidade.

\section{EdUCATION AS A CITIZENSHIP RIGHT AND STATE'S RESPONSIBILITY}

ABSTRACT: The aim of the present text is to reflect upon the relevance of education as a right and condition of citizenship and a function of the State, responsible for its realization. The text is divided in three parts: the first is dedicated to the historical overview of the tenets of the relation between public and private in the beginning of Modernity. The second part approaches education as the condition to the exercise of citizenship, highlighting the role of formal education in this process. The last topic discusses the responsibility of the State is ensuring access to education as an unconditional means to citizenship. Retrieving the liberal ideas from the beginning of modernity and, contrary to the current neoliberal theses, the article defends the point of view that in order to assure quality education for all, State actions are vital.

Key words: Education as a public asset. Education as a right. Education and State. Citizenship. Individuality and society.

* Universidade de Sorocaba (Uniso) e Universidade Estadual de Campinas (Unicamp). Sorocaba/ Campinas (SP) - Brasil.

Contato com o autor: <pedro.goergen@hotmail.com> 


\section{L'ENSEIGNEMENT COMME DROIT DE CITOYENNETÉ ET RESPONSABILITÉ DE L'ETAT}

RÉSUMÉ: L'objet de cette étude est d'envisager la pertinence de l'enseignement comme le droit et la condition de citoyenneté et la fonction de l'État comme responsable de la réalisation de ce droit. Le travail se divise en trois parties. La prémière consacrée au rétablissement historique des présuppositions de la relation entre le public et le privé dans le début de la modernité. La deuxième partie examine l'enseignement comme la condition de l'exercice de la citoyenneté, soulignant le rôle de l'enseignement formel dans ce processus. La dernière partie discute la responsabilisation de l'État comme la garantie d'accès à l'éducation comme un moyen inconditionnel pour la citoyenneté. En récupérant les idées libérales du début de la Modernité et contrairement aux actuelles thèses néolibérales, on défend le point de vue selon lequel la performance de l'État comme garantie de l'éducation de qualité pour tous est indispendable.

Mots-clés: Éducation comme bien publique. Éducation comme droit. Éducation et État. Citoyenneté. Individualité et sociabilité.

\section{Introdução}

$\mathrm{H}$ oje se recoloca de forma enfática o tema da relação entre Estado e sociedade civil. Sabemos que se trata de uma questão antiga. Desde o início da modernidade, quando novas formas de organização e condução social começaram a ser debatidas, os mais ilustres pensadores franceses, britânicos e alemães expuseram suas ideias e divergências a respeito do sentido e função do Estado no novo modelo epistêmico e social emergente. O eixo condutor desses debates eram as demandas de convivência social pacífica, justa, tolerante e a natureza do poder externo capaz de garantir a realização desses anseios.

A Revolução Francesa e a Revolução Americana são certamente os exemplos mais eloquentes dos confrontos teóricos e práticos envolvidos no modelo de uma nova organização e gestão social, livre, dos trabalhadores miseráveis do Terceiro Estado e dos escravos negros. As maiores controvérsias na transição histórica diziam respeito precisamente à questão da justiça, do direito social, da liberdade, da igualdade e, ligado a isto, do sentido e papel do Estado.

Estava em jogo a inauguração de um novo modelo de Estado e de governo, cuja função deveria ser a de garantir o direito à justiça e ao bem-estar de todos os integrantes da comunidade política. Ao longo da história da modernidade, baseada no domínio e manejo racional dos bens materiais e espirituais, o acesso ao conhecimento e à educação foi se tornando condição essencial de sucesso. Delineia-se como consequente e, de certo modo, natural o direito de acesso a tais mecanismos sob a garantia do Estado.

O presente ensaio pretende argumentar (a) que, ao contrário do que insinua o radicalismo neoliberal, a dimensão social e democrática já estava presente desde 
os primórdios do liberalismo; b) que a educação é uma das condições imprescindíveis para a criação de uma sociedade justa e democrática; e c) que estes direitos de todos só podem ser garantidos pela decisiva intervenção do Estado. Antes de tratar diretamente da centralidade da educação como direito e, a seguir, da responsabilidade do Estado pela garantia desses direitos, pretende-se mostrar, em rápidas pinceladas, o caráter já histórico deste debate. Este recuo histórico é importante porque nos ajuda a entender que a consciência do direito, da justiça e do sentido social já estava presente desde o início da Modernidade. É porque tais requisitos se perderam nos descaminhos da Modernidade que hoje seguimos lutando por eles. A barbárie que nos ameaça não é inerente à razão moderna, mas se deve à sua realização distorcida.

\section{Direito, Estado e educação como problema moderno}

Parece haver um consenso em torno dos limites do ser humano em termos de respeito e solidariedade. Os homens são egoístas e desejam posse, poder e domínio. Necessitam, portanto, de orientação, coordenação e mesmo coação para garantir paz, liberdade e vida digna no coletivo. Para evitar a guerra de todos contra todos, Thomas Hobbes (1588-1679), John Locke (1632-1704), Jean-Jacques Rousseau (17121778), Immanuel Kant (1724-1804) e muitos outros sugeriram a realização de um contrato social e a organização de uma estrutura de poder que garantisse relações pacíficas e respeitosas entre todos, como seres humanos.

Ocorre que, neste projeto social, se confrontam dois estatutos de liberdade. De um lado, a liberdade individual e, de outro, a liberdade coletiva, ou, em termos rousseaunianos, o estatuto da liberdade natural e o da liberdade convencional disputam os mesmos espaços, exigindo, portanto, entendimento. O entendimento entre os humanos não parece ser uma tendência natural. Ao contrário, conforme a natureza, prevalece a origem animal do ser humano, ou seja, a imposição da força, o predomínio do mais forte. É bem conhecida a tese de Hobbes (2006, p. 98), segundo a qual "[...] torna-se manifesto que, durante o tempo em que os homens vivem sem um poder comum capaz de os manter a todos em respeito, eles se encontram naquela condição que se chama guerra. Uma guerra que é de todos os homens contra todos os homens".

Para que esta situação de luta possa ser superada, é preciso seguir a razão que "sugere adequadas normas de paz, em torno das quais os homens podem chegar a um acordo" (idem, ibid.). O direito natural de cada um usar livremente a força para impor seus interesses é substituído por um direito legal, na forma de preceitos ou regras gerais, destinadas a regular a vida de todos num ambiente de paz. Esta lei é enunciada por Hobbes (op. cit., p. 102) nos seguintes termos: 
[...] que um homem concorde, conjuntamente com os outros, e na medida em que tal considere necessário para a paz e para a defesa de si mesmo, em renunciar ao seu direito a todas as coisas, contentando-se, em relação aos outros homens, com a mesma liberdade que aos outros homens permite em relação a si mesmo. Pois enquanto cada homem detiver seu direito de fazer tudo quanto queira, a condição de guerra será constante para todos.

Trata-se de instaurar uma instância superior com autoridade suficiente para evitar a guerra e garantir a paz. Para Hobbes, os homens são induzidos a cumprir seus deveres de respeito com os outros apenas por medo diante de um poder delegado a um soberano poderoso, encarregado de zelar pela defesa, pela educação, pela justiça e pela legislação. Embora Hobbes fale de pacto, o Leviatã, senhor absoluto, que poderia ser um monarca ou um parlamento, não deveria ser exposto a qualquer oposição vinda de baixo e nem mesmo ser submisso a qualquer constituição: "Onde não há Estado, entende-se, nada pode ser injusto. A natureza da justiça consiste no cumprimento dos pactos válidos, mas a validade dos pactos só começa com a instituição de um poder civil suficiente para obrigar todos a cumpri-los [...]" (2006, p. 111).

Não há, portanto, dúvida a respeito da posição de Hobbes quanto à melhor estrutura da organização social para evitar a luta de todos contra todos. O filósofo não vê outra maneira de alcançar a paz e garantir os direitos de todos senão mediante o Leviatã, ou seja, o Estado forte o suficiente para impor leis e coagir com sanções os eventuais transgressores.

Embora John Locke não tenha polemizado diretamente com Hobbes (FERGUSON, 2012), sua posição é bastante distinta do absolutismo de Hobbes, que não admitia que o soberano recebesse qualquer oposição vinda de baixo. Locke acreditava na liberdade e na igualdade de todos os homens e, neste sentido, os seus Dois tratados sobre o governo se diferenciam consideravelmente da forma de governo sugerido no Leviatã. Enquanto Hobbes era de certo modo um visionário, que tratava as questões desde o ponto de vista racionalista destituído de qualquer realismo político, Locke acreditava que, pelo pensamento, se poderia modificar as atitudes de toda a sociedade. E isso se confirma, conforme observa Ferguson (2012, p. 140), no fato de que "as ideias de Locke tiveram uma grande influência sobre o desenvolvimento da sociedade e da política na América do Norte". Liberdade, igualdade e direitos são princípios naturais, razão pela qual

[...] não se pode presumir subordinação alguma entre nós que nos possa autorizar a destruir-nos uns aos outros. [...] logo cada um deve, tanto quanto puder, preservar o resto da humanidade, e não pode, a não ser que seja para fazer justiça a um infrator, tirar ou prejudicar a vida ou o que favorece a preservação da vida, liberdade, saúde, integridade ou bens de outrem [...]. A lei da natureza seria vã, como todas as demais leis que dizem respeito ao homem neste mundo, se não houvesse alguém que tivesse, no estado de natureza, um poder para executar essa lei, e, com isso, preservar os inocentes e conter os transgressores. (LOCKE, 2005, p. 385) 
Para que isso seja possível, os homens devem se unir em sociedade e abandonar o estado de natureza. Assim, os homens podem conquistar a liberdade que não é uma "liberdade para cada um fazer o que lhe aprouver", mas a liberdade que "consiste em viver segundo uma regra permanente, comum a todos nessa sociedade e elaborada pelo poder legislativo nela erigido" (idem, ibid., p. 402-403). A razão diz ao homem que ele não pode seguir sempre sua própria vontade se quiser viver em paz e liberdade. Por isso, retira os homens do estado de natureza e os une livremente numa sociedade política, com leis investidas de autoridade para decidir sobre as controvérsias e castigar os infratores. Este modelo de sociedade civil, como se vê, é incompatível com a monarquia absoluta hobbesiana.

Também Hume (2009, p. 541) chega à mesma conclusão ao observar o comportamento contraditório dos ricos, que têm "a obrigação moral de dar aos necessitados uma parte do que lhe é supérfluo", mas não o fazem a não ser obrigados por imposição legal:

Quando os homens descobrem pela experiência que o livre exercício de seu egoísmo e de sua generosidade limitada os torna totalmente incapacitados para a sociedade; e, ao mesmo tempo, observam que a sociedade é necessária para a satisfação dessas próprias paixões, são naturalmente levados a se submeter à restrição de regras que possam tornar seu comércio mais seguro e cômodo.

Portanto, tendo em vista que a benevolência eventualmente presente nos seres humanos não é suficiente para contrabalançar as paixões e apetites naturais, eles são levados a regular suas relações mediante convenções. O apreço pelas condutas convencionadas, além de ser favorecido pelo elogio e pela condenação públicos, necessita ainda da educação e da instrução.

A teoria do Contrato social de Rousseau se aproxima muito mais do modelo de sociedade civil que do absolutismo de Hobbes. Ao sugerir a realização de um contrato para viabilizar a convivência pacífica do ser humano em sociedade, Rousseau (1973, p. 14) parte da constatação de que, "se o homem não tem qualquer autoridade natural sobre os seus semelhantes, se a força não origina direito algum, restam-nos as convenções que, entre os homens, são a base de toda a legítima autoridade".

Como se pode observar, o ponto de partida de Rousseau é diferente do de Hobbes. Sendo a liberdade o que mais qualifica o ser humano, tal contrato não poderia implicar renúncia à liberdade, uma vez que esta é condição da própria natureza humana (ROUSSEAU, 1973). Como proceder então? A conhecida proposta do filósofo genebrino é "encontrar uma forma de associação que defenda e proteja de toda a força comum a pessoa e os bens de cada associado e em que cada um, ao unir-se a todos, só a si mesmo obedeça e continue tão livre como antes" (idem, ibid., p. 21). 
Tal é a essência do Contrato social, sugerido por Rousseau como o único caminho por ele encontrado para garantir a paz de todos, sem tolher a liberdade de cada um: depositar confiança numa autoridade externa, superior e reconhecida por todos.

\begin{abstract}
Cada um de nós põe em comum a pessoa e os bens, sob a suprema direção da vontade geral [...]. Esta associação origina, então, um corpo moral e coletivo constituindo uma unidade, um eu coletivo comum, uma personalidade política que se forma pela união de todas as outras (personalidades) que tinha noutros tempos o nome de cidade e tem hoje o de república ou corpo político, a que seus membros dão o nome de Estado [...]. (p. 22)
\end{abstract}

Este ser coletivo, também chamado de Estado ou de soberano por Rousseau, é formado pelas pessoas que, individualmente, se denominam cidadãos e, coletivamente, povo. É nessa condição que, de certo modo, o indivíduo abre mão de parte de sua liberdade particular ou natural, da qual não pode fruir isoladamente, em favor da liberdade coletiva que o Estado, ou seja, o contrato lhe garante. Ao unir-se a todos, cada um obedece a si mesmo, permanecendo livre como antes (ROUSSEAU, op. cit., p. 21). Pela união de todos forma-se um corpo político que exerce o poder sobre todos não por força de poderes estranhos, mas por concessão de todos os membros. Dessa forma, "o pacto social estabelece entre os cidadãos uma tal igualdade que todos ficam obrigados às mesmas condições e todos devem gozar dos mesmos direitos" (ibid., p. 41).

Estas ideias de Rousseau influenciaram Immanuel Kant, outro pensador fundamental do início da Modernidade. O filósofo inicia seu breve escrito Sobre a paz perpétua, dizendo que a paz não é um estado de natureza, mas que, ao contrário, "o estado de natureza é, de fato, a guerra" (KANT, 2010, p. 39). Um estado em que, em função das hostilidades e da ameaça de hostilidades, os homens se tratam como inimigos, impedindo a segurança e a paz. Estas só podem ser conquistadas num "estado" civil, embasado numa constituição fundada nos princípios da "liberdade dos membros de uma sociedade enquanto homens"; de "'dependência' de uma legislação comum enquanto súditos"; e de "igualdade' de todos enquanto cidadãos". Esta constituição "emana da ideia do contrato original sobre o qual se deve fundar toda a legislação de um povo. Tal constituição é republicana" (idem, ibid., p. 41). Constituição republicana é aquela que se fundamenta no "ato da vontade geral, que converte a multidão em povo" (p. 45).

Este pacto representa a passagem de "multidão" para "povo", condição em que as pessoas se submetem e limitam sua "selvagem e irrefreável liberdade" às leis gerais, públicas e coativas, válidas para todos. Submeter-se a preceitos gerais, dominando as tendências egoístas, certamente não é fácil e não acontece de forma natural. Ironicamente, a ajuda vem dessas mesmas disposições egoístas naturais que precisam ser reprimidas para se obter paz e liberdade. Os efeitos destruidores do choque 
entre tendências egoístas justificam a instalação racional a favor da implantação do Estado capaz de arbitrar, tendo como objetivo a justiça e o bem comum. Dessa forma, o ser humano, apesar de suas tendências egoístas, pode ser racionalmente obrigado a ser um bom cidadão. O próprio Kant (op. cit., p. 77) resume:

Eis aqui uma multidão de seres racionais que desejam coletivamente leis universais para a sua própria conservação, mesmo quando cada um deles, no seu recôndito, se inclina sempre a iludir a lei. Trata-se de ordenar a vida dos mesmos em constituição, de tal sorte que, ainda que os seus sentimentos íntimos sejam opostos e hostis uns a outros, fiquem refreados, e o resultado público da conduta desses seres seja exatamente idêntico ao que ocorreria se não tivessem mais instintos.

Não se trata da melhora moral do ser humano, mas de dispor suas inclinações egoístas e hostis de tal modo que "todos os indivíduos se sintam obrigados pela força a submeter-se às leis e tenham que viver imperiosamente em relações pacíficas, obedecendo às leis" (idem, ibid.). Não é, portanto, a moralidade do homem que produz uma constituição, mas, inversamente, é a constituição que contribui para a educação moral do povo. Dessa disposição Kant conclui que não há oposição entre moral e política. Ao contrário, a moral do povo exige honradez política que promova a unidade coletiva da vontade geral, de modo que todos juntos desejem este Estado de unidade total da sociedade civil (Kant, op. cit., p. 89). "A paz entre os homens que convivem", conclui Kant, "não é um estado de natureza; o estado de natureza é, de fato, a guerra [...] e a paz é algo que deve ser instaurado" (p. 95). É a maldade da natureza humana que torna necessária a coação.

Esta rápida incursão no pensamento político desses quatro pensadores permite concluir que havia, desde o início da Modernidade, muita clareza a respeito da necessidade de uma instância superior como garantia de liberdade e convivência pacífica entre os seres humanos, independentemente do nome que lhe fosse dado e dos argumentos usados para justificá-la.

\section{A educação como condição inalienável do direito à cidadania}

Constata-se, portanto, como foi dito no início da seção anterior, que neste projeto social se confrontam dois modelos ou estatutos de liberdade: a liberdade individual e a liberdade coletiva, ambas tendendo a ocupar os mesmos espaços e exigindo, portanto, entendimento. Mesmo concordando com Bobbio (2003) que o direito público é uma conquista tardia da humanidade, sabemos que o conflito entre o público e o privado existe desde os primórdios da vida humana em sociedade. Já Aristóteles (1999, p. 18) havia dito: "ainda que a finalidade seja a mesma para um homem isoladamente e para a cidade, a finalidade da cidade parece de qualquer 
modo maior e mais completa [...]". A experiência histórica nos mostra também que o entendimento entre os interesses públicos e privados não acontece de forma natural. De fato, nunca o ser humano superou sua origem e seu lado animal, conforme mostram as constantes investidas de antepor o privado ao público. A cultura humana é, precisamente, o consciente esforço de um equilíbrio entre os interesses individuais/ privados e os sociais/públicos, sem negação radical de nenhum dos dois.

Historicamente, este objetivo nunca se realizou plenamente. Ao contrário, ao longo dos tempos, configurou-se uma sociedade dividida entre fortes e fracos, dominadores e dominados, ricos e pobres, incluídos e excluídos. Partindo da premissa de que, em princípio, e apesar das diferenças genéticas e socioeconômicas, somos todos iguais como seres humanos, conclui-se que os socialmente desfavorecidos necessitam, em termos de educação, de amparo num duplo sentido. Primeiro, mediante uma educação escolar democrática, visando um novo modelo de cidadania participativa e tendo por objetivo a construção de uma nova sociedade mais digna e justa. Segundo, pela garantia de oferta e acesso à educação de qualidade para todos sob a responsabilidade do Estado. A seguir, farei algumas considerações a respeito deste primeiro ponto e, no item seguinte, a respeito do segundo.

O fio condutor dos debates, historicamente focados na temática da relação entre indivíduo e sociedade, passa por modelos de organização social que ora acentuam o lado individual, ora o comunitário. Cerda et al. (2004) reúnem estas duas configurações sob os termos genéricos de liberalismo e comunitarismo, destacando, respectivamente, a ênfase no individual ou no social. Cada um destes modelos se embasa e diferencia segundo determinadas noções de cidadania, democracia, política e sociedade. No centro do debate encontram-se a noção de cidadania e seus eixos referentes à igualdade, ao cumprimento da lei e à participação política.

O liberalismo valoriza o lado individual, destacando como função do Estado a proteção da autonomia, da liberdade e dos direitos de cada um. Esta opção política se embasa em amplos e complexos debates sobre a definição de igualdade, de direito e das formas de participação política. Seja como for, para o liberalismo, o individual precede o público, sendo que o Estado e seu aparato jurídico/legal não podem se antepor aos direitos de liberdade e autonomia do indivíduo. Mesmo assim, Locke (2005, p. 491), apesar de afirmar que todo o homem é "naturalmente livre, sem que nada possa colocá-lo em sujeição a qualquer poder terreno a não ser o seu próprio consentimento", acrescenta que o exercício da liberdade natural não é possível sem a proteção da sociedade, em função das ameaças e dos perigos constantes vindos daqueles que não observam a justiça e equidade. Por isso, "[...] não é sem razão que ele [indivíduo] procura e almeja unir-se em sociedade com os outros que já se encontram reunidos ou projetam unir-se para a mútua conservação de suas vidas, liberdades e bens, aos quais atribuo o termo genérico de propriedade" (Locke, op. cit., p. 495). 
Esta abertura ao social, que encontramos na origem do liberalismo e que depois foi esquecida, torna-se prioritária para o comunitarismo, que privilegia o lado social da relação indivíduo/sociedade. Segundo este ideário político, a comunidade tem precedência sobre o indivíduo, para o qual a participação política é essencial não só para sua vida social, mas também para a constituição de si mesmo como sujeito individual. Reforça-se a importância dos vínculos sociais, considerando que tais vínculos determinam as pessoas, suas formas de entendimento e conduta. Nestes termos, inversamente ao visto anteriormente, o indivíduo cidadão se forma mediante a participação política no interior de um contexto de ideias, atitudes e virtudes cívicas. Cerda et al. (2004, p. 15) resumem esta questão nos seguintes termos:

O essencial no debate liberal-comunitário se encontra, então, no fato de que para os primeiros a filosofia pública deveria estar determinada pela autonomia do indivíduo e o caráter neutro do Estado; para os segundos, a proteção que o liberalismo gera em torno do indivíduo, longe de exaltar os direitos destes frente ao Estado, nada mais faz senão debilitar "o horizonte de significação" do coletivo, na medida em que fomenta um individualismo extremo.

Pode-se dizer, portanto, que, respeitadas as profundas diferenças nos pontos de partida e de chegada em termos de democracia, sobretudo no que se refere à inclusão/exclusão, ambos os modelos reconhecem que a identidade do sujeito depende, em boa medida, da relação deste com a comunidade política. Dito assim parece simples e certamente conciliador demais. Mas, considerando o grande esforço dos autores lembrados na primeira parte, sabemos que está em jogo uma das mais complexas e conflituosas questões da convivência social e política humana. Trata-se de ajustar o comportamento individual, naturalmente egocêntrico, aos interesses comuns, de modo a garantir aos mais fracos direitos iguais de acesso aos bens matérias e culturais produzidos pela humanidade.

O liberalismo e o comunitarismo sustentam duas noções distintas de autonomia. O liberalismo concebe os indivíduos como sujeitos livres e autônomos antes mesmo de participarem da sociedade. Não é a sociedade que agrega racionalidade ao sujeito, mas é este que, com sua racionalidade, funda a sociedade pela celebração de um contrato. Os comunitaristas, ao contrário, entendem que o sujeito "somente se constitui como tal na sociedade, colocando no centro da reflexão a noção de pertinência"' (Cerda et al., 2004, p. 20).

Tomadas em suas expressões mais radicais, ambos os posicionamentos implicam consequências complexas e difíceis de serem assumidas: de um lado, a defesa da autonomia radical do indivíduo frente à sociedade e, de outro, o integrismo que restringe o indivíduo e sua autonomia frente às influências e valores coletivos. Cerda et al. (2004, p. 21) sugerem o conceito de "cidadão" como metáfora "para entender 
a articulação entre as responsabilidades que os cidadãos têm como membros de redes sociais mais amplas e o desenvolvimento da liberdade e da autonomia individual".

De fato, independente do ponto de partida inicial, ao contrário de uma contraposição entre indivíduo e comunidade, constata-se uma complementariedade que, se não pode ser considerada natural, é seguramente uma condição social. Nem a sociedade pode desconsiderar a liberdade e autonomia relativa dos indivíduos, nem o indivíduo pode se imaginar livre das fundamentais marcas nele impressas pela convivência social. Liberdade e autonomia se desenvolvem e se limitam no coletivo e é no coletivo que adquirem seu real e mais profundo sentido de cidadania. Cidadania que expressa a verdadeira realização individual e social do ser humano, adquirindo, assim, a condição de direito.

Para que o direito seja atendido, isto é, para que o sujeito possa se tornar cidadão, é necessário habilitá-lo à convivência social. Isto, por sua vez, exige a capacidade de expressar seus ideais, interesses e necessidades e defender seus direitos no espaço público. Precisa, além disso, ter condições de participar de todo o processo social que lhe garanta a vida digna, em termos de trabalho e emprego para a sua sobrevivência em condições dignas. Ou, para dizê-lo de outra maneira, ele precisa ter condições de acesso aos bens materiais e culturais produzidos pela sociedade. Para que isso seja possível, é necessário desenvolver suas potencialidades de domínio dos conhecimentos e habilidades, bem como o manejo dos códigos de comunicação indispensáveis à argumentação.

A cidadania está relacionada à capacidade de intervir tanto nos espaços privados da ordem econômica, quanto nos assuntos públicos de ordem política. Só essa dupla capacidade e habilidade leva o sujeito a ultrapassar o umbral da simples e formal posse de direitos e alcançar o que se pode chamar de cidadania ativa, ou seja, a verdadeira participação no modelo democrático. São múltiplos os caminhos para adquirir tais capacidades e habilidades, mas o principal deles é, sem dúvida, a educação. E, mesmo hoje, quando está à disposição uma infinidade de processos educativos, a educação formal continua sendo absolutamente imprescindível ao exercício da cidadania. Nenhum dos demais recursos como, p. ex., os recursos midiáticos, pode suprir a educação formal e sistemática oferecida pela escola. Apesar de suas inúmeras deficiências, limites e problemas, ela continua sendo o principal recurso de formação para a cidadania com tudo o que isso implica. É, portanto, lógico que o exercício da cidadania, certamente o principal direito do ser humano como ser social, pressupõe o acesso à educação. Disso se depreende que a sociedade democrática, em seu sentido pleno, é aquela em que todos os seus integrantes têm acesso à educação, e uma educação de qualidade tal que lhe dê condições para o exercício pleno da cidadania. 
O que significa ter acesso à educação é, sem dúvida, uma questão nada fácil de ser respondida no contexto da sociedade contemporânea. Se até algumas décadas atrás ainda existiam razoáveis consensos em termos de estrutura e organização social, de valores e de formas de comportamento que serviam de orientação para o processo educativo, atualmente até estes paradigmas mínimos se desestabilizaram. Na sociedade intercultural, midiática e globalizada existem e incidem educativamente sobre o indivíduo múltiplas e contraditórias referências culturais e ideológicas. O tradicional conceito de "capital social" - entendido como o conjunto de relações, normas, valores, conhecimentos, entre outros, legitimados socialmente - muda de figura com a interferência do estranho, do outro, da alteridade.

Esta incidência interfere na autodeterminação tanto individual quanto coletiva. Em termos tradicionais, o capital social era, de certa forma, familiar a todos, conquanto fizesse parte da tradição comunitária. Constituía um conjunto de referências no qual o indivíduo se sentia ambientado como integrante de uma tradição familiar e comunitária, numa relação de mútuas referências. Este vínculo, tão bem traduzido na expressão "nós", desestabiliza-se pela vinda do "estranho", gerando uma situação de suspeita nunca antes vivida com tal intensidade. Frente a essa multiversidade, cabe ao sujeito entender, tomar posição, aceitar ou rejeitar, e, antes de tudo, dialogar criticamente com estas diferenças.

Em nenhum outro momento se enfatizou tanto este tema em termos de tarefa educativa quanto hoje. E isto por dois motivos principais. De um lado, porque a escola pode e deve ajudar o diferente excluído, não importando se por razões étnicas, ideológicas ou econômicas, a ter acesso aos conhecimentos e habilidades necessários à cidadania plena; de outro, porque a escola pode e deve estimular o pensamento crítico sobre o caráter desumano da exclusão e da intolerância. É evidente que as instituições (família, mídia, igreja, entre outras) que, de uma forma ou de outra, participam do processo educativo na sociedade devem partilhar desta responsabilidade. Não obstante, a primeira entre todas deve ser a escola, porque é ali, como em nenhum outro, o lugar da formação, do ensino sistemático e planejado, do contato com a cultura, da socialização com o outro, o diferente.

A educação formal, como se sabe, é um processo lento que envolve a formação do ser humano como um todo, em suas dimensões epistêmicas, éticas e estéticas, que não se ajusta ao ritmo acelerado e aligeirado do modelo pragmático/ utilitarista da sociedade contemporânea. Como não se pode esperar a desaceleração ou a interrupção próxima deste movimento e tendo em vista, também, a necessidade de preparar as pessoas para viver nesta realidade, a única saída viável é tratar de torná-las capazes de interatuar criticamente no contexto da sociedade complexa e economicamente determinada. Nas condições atuais não temos como fugir dessa ambivalência. Mesmo assumindo um ponto de vista revolucionário, seria ilusório 
imaginar, nas condições atuais, a ruptura súbita com as exigências pragmáticas da vida no interior do sistema vigente. Há, portanto, que viver nesta realidade e é a escola o espaço onde se pode e se deve aprender a viver em sociedade, inclusive em termos de sua transformação.

Por ora, não consigo realisticamente entrever outro caminho senão o de oferecer uma educação que proporcione aos sujeitos certo núcleo identitário, estruturante de um espaço de autonomia e independência frente às determinações econômicas. Para tanto, o ser humano precisa aprender a agir a partir de dois núcleos referenciais: o da permanência e o da mudança. Só isso lhe possibilita tanto, de um lado, atender aos requisitos postos pela sociedade real, para a qual, bem ou mal, as pessoas precisam ser preparadas, quanto, de outro, evitar que a integração anule o sujeito consciente, ativo e transformador.

Dessas considerações gerais é possível tirar algumas conclusões, a meu ver, bastante relevantes para o nosso objetivo: a) devemos reconhecer que, em qualquer circunstância, o acesso à educação formal é condição fundamental para a formação de cidadãos conscientes, críticos e democráticos, capazes de promover a transformação social. A escola continua sendo, por excelência, o espaço no qual se pode promover o comportamento reflexivo-crítico indispensável à cidadania ativa, com identidade e pertinência, visando um projeto coletivo de convivência verdadeiramente democrático; b) Ao contrário do que muitas vezes se afirma, a educação escolar não perde em relevância frente ao crescimento dos espaços informais de educação, tais como a mídia e os meios eletrônicos de comunicação. Estes recursos mais recentes, embora importantes se bem usados, não suprem a tarefa formativa sistemática da educação formal; c) A educação formal precisa ser hoje repensada na perspectiva da realidade complexa, plural, fluente, globalizada e multicultural, tanto em termos de procedimentos pedagógicos quanto de conteúdos e de formação cidadã. Podemos, então, concluir que o acesso à educação formal de qualidade é condição inalienável do direito à cidadania.

\section{A educação como direito e responsabilização do Estado}

Inicialmente, tentei mostrar que, desde os primórdios da Modernidade e do pensamento liberal, havia o reconhecimento da necessidade de um equilíbrio entre as tendências individualistas e as exigências da convivência social. A forma de alcançar este equilíbrio seria a celebração de um contrato de respeito mútuo e a criação de uma instância superior, reconhecida por todos, na forma de Estado, forte o suficiente para impor respeito às disposições desse contrato. Num segundo momento, argumentei que a educação é uma condição necessária para o exercício da cidadania, constituindo-se, portanto, num direito de todos e de cada um. Na sequência, quero 
tecer algumas considerações sobre a necessidade de garantir a efetivação do direito formal à educação como direito de fato, sendo o Estado o agente responsável pelo acesso de todos a uma educação de qualidade.

O liberalismo, como expressão filosófico-política da valorização do indivíduo nos primórdios da Modernidade, alcança sua expressão mais radical no atual neoliberalismo. $\mathrm{O}$ individualismo extremado e a exacerbada priorização do privado/ econômico frente às outras dimensões do humano são suas características mais aparentes. Presente desde o início, a tese da inviolabilidade dos direitos individuais, em especial o da propriedade privada na formulação de Locke (2005), encontra sua mais forte expressão político/econômica no argumento da livre determinação do indivíduo frente ao Estado.

Tal postura filosófica, na origem proveniente da luta contra o absolutismo medieval, assume hoje, após longa trajetória de embates travados no decorrer de toda a Modernidade, características limítrofes na forma de um inusitado economicismo privatista. Sua escalada mais decisiva aconteceu nos anos 80 e 90 do século passado, incidindo sobre a relação entre direitos individuais/privados e prerrogativas sociocomunitárias. O confronto se dá, agora, entre a esfera privada e a esfera pública, esta última representada pelo Estado. Envolvem-se nessa radicalização os mais importantes agentes do capitalismo neoliberal, tais como o Banco Mundial (BM), o Fundo Monetário Internacional (FMI), o Banco Interamericano de Desenvolvimento (BID) e a Organização Mundial do Comércio (OMC). Esses organismos se encarregam de executar o receituário do Consenso de Washington, de 1989, que consagra os interesses do capital internacional e destrói as bases sociais do Estado de bem-estar social, instaurado após a Segunda Guerra Mundial. Com a ascensão do econômico (leia-se mercado) ao posto de valor absoluto e prioritário, o Estado, acusado de dispendioso e moroso, passou a ser considerado o grande vilão do mau desempenho econômico e, na mesma lógica, do próprio desenvolvimento social. Assim sendo, o Estado deveria manter-se neutro e restrito aos setores não atraentes para o setor privado.

Ao priorizar a iniciativa privada e a livre concorrência como estratégia de autorregulação das relações econômicas e sociais, parte-se da falsa premissa de que todos os indivíduos têm iguais condições de competir. Só este (falso) pressuposto permite imaginar que a regulação das relações sociais pelo mercado concorrencial tem sentido democrático. De todos os modos, o liberalismo e, de forma extremada, o neoliberalismo acreditam que as relações sociais podem ser democraticamente articuladas mediante a livre concorrência. Esta leitura baseia-se, como pretendo mostrar, numa interpretação errônea e unilateral dos próprios princípios do liberalismo clássico. Em consequência, agentes externos à engrenagem capitalista movida pelas águas turvas da concorrência e do lucro, não adaptados ao modus operandi próprio do mercado, devem ser impedidos de interferir no jogo das relações econômicas. 
Aos interesses liberais/individualistas se contrapõe o princípio social/comunitarista, segundo o qual a prioridade não pertence aos indivíduos ou grupos, mas sim ao social como um todo. A afirmação de Aristóteles referente à precedência do social frente ao individual, mencionada anteriormente, não deixou de ser, desde então, paradigmática no debate nunca esmaecido entre o privado e o público. No caso da prevalência do público, a democracia passa a ser definida como um sistema coletivo baseado num ordenamento jurídico, para o qual os cidadãos podem e devem concorrer livre e participativamente no espaço público.

Nesse sentido, embora indivíduo e sociedade se pressuponham mutuamente, a própria ideia de bem não é exterior, como no caso do predomínio do individual, mas originária da própria comunidade, ou seja, a identidade dos sujeitos não é precedente, senão que construída na própria vida coletiva dos indivíduos. Formulando de outra maneira, pode-se dizer que, a partir dos aportes naturais, a identidade de cada um se constitui na cultura. Daí o essencial sentido de democracia assim formulado por Cerda et al. (2004, p. 17): “a democracia deve ser um sistema que expresse politicamente a comunidade. Daí decorre que deve ser entendida como um regime substantivo que, ao pretender dar conta da comunidade, assume articular-se em torno de uma concepção compartida de bem".

Entendida dessa forma, nos termos desses mesmos autores (2004, p. 18-19),

[...] a ação política tem como um núcleo a (auto)consciência dos indivíduos como sujeitos pertencentes a uma comunidade, concebida como um todo que dota de sentido a existência individual [...]. Deste modo, se assume que a identidade se desenvolve necessariamente no espaço público e, portanto, a política (como atividade do público) constitui uma parte ativa da construção da identidade.

Na acepção deste ponto de vista, partilhado pelo autor deste trabalho, pode-se concluir logicamente que as condições para a participação democrática no espaço público constituem um direito de todos e de cada um, porquanto tal participação representa a possibilidade de constituição da identidade e, portanto, a realização do ser humano. Aceitando a óbvia premissa de que sem educação não há cidadania, pode-se concluir que a educação é, efetivamente, um direito essencial de cada cidadão. Considerando, ainda, que estas condições não são dadas naturalmente, mas precisam sim ser adquiridas, pode-se afirmar também como pressuposto de toda sociedade efetivamente democrática a garantia de realização destes direitos, ou seja, no caso específico da educação aqui em pauta, que o direito à educação deve ser garantido a todos.

Ainda que o Brasil não tenha vivido a experiência política e social do Estado de bem-estar, o acirramento do privatismo mercadológico neoliberal refletiu-se de maneira drástica sobre alguns setores, entre eles também a educação. Com isso, o 
neoliberalismo assume uma dimensão de barbárie social que contradiz, a meu ver, a própria tradição liberal que, apesar do acento posto no individual e no privado, sempre ostentou uma preocupação maior com a justiça social.

A contraposição entre o liberalismo e o comunitarismo sofreu um forte acirramento a partir das décadas de 1980/1990, quando a orientação política, cedendo às pressões econômicas, passou a exigir uma drástica redução da presença do Estado. Apesar do virulento e bárbaro economicismo neoliberal, é possível afirmar que ambos os modelos coincidem no reconhecimento da necessidade de alguma forma de regulação social. Ainda que o economicismo neoliberal admita que a diferença não é de princípio mas de grau, a condição é que o mercado continue a ditar os rumos. Nesse sentido, ao se conceder o poder a uma autoridade externa e neutra, tal como o Estado, imediatamente surge a pergunta a respeito dos procedimentos e dos limites dessa instituição frente ao âmbito privado. Questiona-se quais as origens e fundamentos que o legitimam e como se acondicionam as ações do Estado com relação aos direitos individuais/privados, postos como naturais.

Conforme procurei mostrar na primeira parte deste trabalho, os grandes pensadores, que na origem contribuíram para estas orientações históricas, tinham consciência muito clara a respeito das dificuldades e lutas que o processo civilizatório exigiria. Sabiam, e o disseram explicitamente, que seria necessário um poder regulador responsável pelo equilíbrio entre os interesses privados e coletivos ou públicos. Adam Smith (1983, p. 214), considerado um dos fundadores e principais teóricos do liberalismo econômico, ao comentar o atraso e a ignorância da vasta maioria das camadas baixas, condenadas ao trabalho repetitivo e entorpecente que as tornava incapazes de se interessar e formar juízos a respeito dos grandes problemas do país, admite que "a educação das pessoas comuns talvez exija, em uma sociedade civilizada e comercial, mais atenção por parte do Estado que as pessoas de alguma posição e fortuna". Lendo com atenção a Riqueza das nações, percebe-se claramente sua opinião de que a educação do povo não é possível sem a ajuda do Estado. "Ainda que o Estado não aufira nenhuma vantagem da instrução das camadas inferiores do povo, mesmo assim deveria procurar evitar que elas permaneçam totalmente sem instrução" (SMITH, op. cit., p. 217).

Semelhante raciocínio poderia ser desenvolvido recorrendo ao campo da filosofia pragmática, por exemplo, com Locke (2005) e Hume (2009), defensores de uma educação útil, pela qual entendiam uma educação para a felicidade de todos, fosse ela o desenvolvimento dos dons naturais ou a biografia sobre uma folha em branco. Também podemos lembrar Kant com seus conceitos de paz perpétua, esclarecimento e formação, com os quais não pretendia indicar o esclarecimento como um estágio alcançado, mas como um processo histórico de organização social e individual a ser conduzido pela razão humana. 
Trata-se, como sabe o filósofo, de uma busca permanente, em circunstâncias históricas variáveis, de formas de organização e de autoridade, capazes de garantir a convivência humana, tendo na razão o princípio ordenador tanto da sociedade, quanto das mentes. Havia ocorrido uma mudança profunda: o homem tomava para si a responsabilidade de projetar o seu mundo, mas era sabido que isto não seria tão simples quanto o entusiasmo racionalista posterior imaginaria. Em termos mais contemporâneos, Smith e Kant sabiam que a educação das pessoas, especialmente as mais carentes, necessita do apoio e da garantia do Estado.

Para completar essas considerações históricas, podemos lembrar ainda Wilhelm von Humboldt (1767-1835), um dos mais representativos pensadores do liberalismo alemão. Suas críticas a "qualquer interferência do Estado em assuntos particulares - em que não ocorra qualquer violência aos direitos individuais - deveria ser absolutamente condenada" (2004, p. 153) e sua defesa da riqueza do livre jogo na pluralidade indivíduos devem ser entendidas no contexto do absolutismo político e da emergente subjetividade do século XVIII. Como ministro da Educação, Humboldt promoveu amplas reformas educacionais, visando a inovação curricular, a formação de professores e o sistema de avaliação. Isso evidencia que, ao contrário do que parecem insinuar suas críticas, ele era favorável à intervenção do Estado, que deveria promover a verdadeira Bildung dos cidadãos. Só a educação integral, promovida pelo Estado no sistema público de educação, daria às pessoas condições para o exercício da cidadania. Em suas palavras (ibid., p. 295), “[...] a segurança dos cidadãos numa sociedade depende principalmente da transferência ao Estado de toda a busca por reparação. Com esta atribuição o Estado adquire a obrigação de dar aos cidadãos aquilo que eles talvez não mais obtenham por si mesmos".

O abalo neoliberal restringe a responsabilização do Estado pela garantia dos direitos de todos à cidadania, particularmente nas áreas de saúde e educação, não por acaso as mais onerosas e, ao mesmo tempo, as mais promissoras para a exploração econômica. Estão em jogo, de um lado, a minimalização do Estado e a degradação da educação a produto comercializável segundo as leis do mercado e, de outro, a crescente privatização do próprio Estado, posto a serviço de interesses privados. A crise econômica europeia, o uso de recursos públicos para o saneamento dos bancos, falido centro nervoso do capitalismo selvagem neoliberal, e a adaptação da educação superior às contingências e exigências do mercado internacional são exemplos que falam por si. Está em jogo a relação entre o Estado como instituição responsável pela democracia e justiça social e a educação como direito de todos e como condição incontornável do exercício da cidadania e da democracia.

Nas sociedades complexas de hoje, dominadas pela pragmática econômica, as relações entre Estado e educação tornaram-se também complexas. $\mathrm{O}$ tema da relação entre o público e o privado, entre o individual e o coletivo, entre a regulação 
e a liberalidade, entre o humano e o mercantil, entre a formação e a competência, entre a autonomia e a instrumentalização, entre a pessoa e o sistema está hoje na ordem do dia no mundo inteiro. O interessante artigo de Robertson e Verger (2012) sobre as parcerias público-privadas nos revela a complexidade do tema e os encaminhamentos que vêm sendo dados para a sua solução. Segundo esses autores (2012, p. 1136),

\begin{abstract}
Como parte do projeto neoliberal, lançou-se, na década de 1980, um conjunto de ideiaschave com destaque para: a fragmentação das políticas estatais protecionistas, de modo a facilitar a livre movimentação do comércio, das finanças e do trabalho através das fronteiras nacionais (conhecida como desregulação); a implementação de políticas de concorrência entre os setores público e privado destinadas à criação de eficiência; a privatização de uma série de antigas atividades estatais e seu redimensionamento (envolvendo um processo dual de descentralização e recentralização). O estatuto especial das atividades do Estado como "serviços públicos" ou não seria mais aplicável ou necessitaria ser radicalmente repensado.
\end{abstract}

Bobbio (2003) nos ajuda a entender que se trata de dois modelos de sociedade: a do citoyen, ou interesse público, e a sociedade do bourgeois, ou interesse privado. Ambos baseiam-se em dois modelos distintos de direito: o direito público, com normas vinculatórias postas pelo poder político e reforçadas pela coação, e o direito privado regido por normas estabelecidas pelos singulares em contrato para regular suas relações. Bobbio (op. cit., p. 27) busca uma solução conciliatória ao sugerir que:

[...] os dois processos, de publicização do privado e de privatização do público, não são de fato incompatíveis, e realmente compenetram-se um noutro. O primeiro reflete o processo de subordinação dos interesses do privado aos interesses da coletividade representado pelo Estado, que invade e engloba progressivamente a sociedade civil; o segundo representa a revanche dos interesses privados através da formação dos grandes grupos, que se servem dos aparatos públicos para o alcance dos próprios objetivos.

O primeiro e maior interesse do neoliberalismo privatista é que os rumos da sociedade sejam submetidos às leis do mercado e o Estado seja reduzido ao mínimo necessário ao "bom" funcionamento do sistema. Dessa forma, os interesses sistêmico-econômicos se sobrepõem aos genuínos interesses dos cidadãos. Um desses interesses é o direito à educação. Sendo a educação condição sine qua non de equidade social e sendo este o sentido maior do Estado, ele deve garantir o acesso à educação de qualidade para todos.

Até em países desenvolvidos, conforme reconhecem Robertson e Verger (op. cit., p. 1137),

[...] este repertório político que incluía a descentralização, a privatização e a cobrança de taxas teve consequências devastadoras não só na qualidade e na capacidade desses 
sistemas de ensino, mas também para as sociedades como um todo nas quais se inserem, tendo em vista a crescente polarização social e os níveis de desigualdade.

Podemos, então, bem imaginar o que ameaça ocorrer em países subdesenvolvidos ou em desenvolvimento com os graves problemas de decalagem social. Eu arriscaria dizer que o maior risco em tais situações é a naturalização da exclusão cultural e econômica de amplas camadas da população. O resultado final seria a completa instrumentalização do indivíduo e a total privatização do Estado, ou seja, restaria o mercado nu e cru, com tudo o que isso significa. Seria a barbárie da qual, segundo muitos, estamos nos aproximando perigosamente. Trata-se de uma questão que talvez deva ser pensada como inerente à própria condição humana de individualidade e coletividade, de seres egoístas e altruístas que somos. Sabemos que o altruísmo, o respeito e a tolerância com o outro são fundamentais para a convivência e a democracia, por sua vez, condições essenciais à cidadania de todos. Para que a socialidade não sucumba diante de devastador impulso privatista - hoje tão assustador, sobretudo, porque seu interesse não está focado na educação e formação das pessoas, mas no lucro -, é crucial a atuação reguladora do Estado. O cuidado com a educação como bem público acessível a todos é certamente o mais importante recurso de que o Estado pode dispor para a realização de sua mais importante função: garantir vida digna e justa de todos em sociedade.

\section{Conclusão}

Na primeira parte do presente estudo, fez-se um breve recorrido pela história do pensamento liberal na tentativa de mostrar que os principais autores, ao contrário do que muitas vezes se supõe, sempre admitiram e consideraram indispensável a intervenção do poder público como forma de controlar o natural conflito entre os interesses privados e a necessidade da convivência social. A criação de uma instância superior, aceita e respeitada por todos com base num contrato social, tem o sentido de ordenar a convivência pacífica e respeitosa entre os direitos de todos os indivíduos, sob os auspícios da lei e mesmo da coação.

O passo seguinte foi mostrar que a educação é condição inarredável para o exercício da cidadania, constituindo-se, portanto, em direito fundamental de todos os seres humanos. Em especial nas sociedades complexas e economicamente embasadas no conhecimento, aqueles que não têm acesso à educação são impedidos de participar da vida tanto cultural quanto econômica da sociedade. Mais que isso, os sujeitos são prejudicados na sua realização como seres humanos, uma vez que a identidade do sujeito se constitui em sociedade.

Desses passos anteriores concluiu-se que o Estado, como instância responsável pela convivência digna e justa entre os indivíduos, tem como dever e responsabilidade 
garantir o acesso de todos à educação. Esta responsabilização do Estado enfrenta hoje forte oposição por parte dos estrategistas neoliberais, defensores dos direitos privados e da livre concorrência como melhor forma de organização social. Condenando o Estado por considerá-lo oneroso e ineficiente e interessados num novo segmento de mercado e lucro, defendem a privatização da educação e sua submissão às leis do mercado. Restringindo o acesso à educação àqueles que podem pagar por ela, transformam-na em mero produto. Esta estratégia, além de opor-se, em princípio, ao conceito de educação como direito de todos, consagra a desigualdade social e impede a realização dos seres humanos como sujeitos e cidadãos. Frente aos nefastos efeitos desta política implantada ao longo das três últimas décadas, e considerando também a inarredável necessidade do acesso à educação de qualidade como condição de realização humana e de justiça social, defende-se a responsabilização do Estado pelo direito de todos à educação de qualidade.

\section{Referências}

ARISTÓTELES. Ética a Nicômacos. Brasília, df: Editora da UnB, 1999.

BOBBIO, N. Estado, governo, sociedade: para uma teoria geral da política. Rio de Janeiro: Paz \& Terra, 2003.

CERDA, A. et al. El complejo caminho de la formación ciudadana. Santiago: LOM, 2004.

CONDORCET, M.J.A.N.C. Cinco memórias sobre a instrução pública. São Paulo: Unesp, 2008.

FERGUSON, N. Civilização: Ocidente x Oriente. São Paulo: Planeta, 2012.

HIMMELFARB, G. Os caminhos para a modernidade: os iluminismos britânico, francês e americano. São Paulo: Realizações, 1911.

HOBBES, T. Leviatã ou matéria, forma e poder de um Estado eclesiástico e civil. São Paulo: Martin Claret, 2006.

HUMBOLDT, W. Os limites da ação do Estado. Rio de Janeiro: Topbooks, 2004.

HUME, D. Tratado da natureza humana. São Paulo: Unesp, 2009.

KANT, I. Zum ewigen Frieden: rumo à paz perpétua. São Paulo: Ícone, 2010.

LOCKE, J. Dois tratados sobre o governo. São Paulo: Martins Fontes, 2005.

ROBERTSON, S.; VERGER, A. A origem das parcerias publico-privada na governança global da educação. Educação \& Sociedade, Campinas, v. 33, n. 121, p. 11331156, 2012. 
A educação como direito de cidadania e responsabilidade do Estado

ROUSSEAU, J.-J. Contrato social. Lisboa: Presença, 1973.

SMITH, A. A riqueza das nações. São Paulo: Abril Cultural, 1983. v. 2.

Recebido em 10 de junho de 2013.

Aprovado em 16 de julho de 2013. 